\title{
Using Sketchnotes in PhD Research and Academic Practice
}

\author{
Deborah Baff
}

\author{
Lancaster University, United Kingdom
}

\begin{abstract}
This paper is a reflective account of using Sketchnotes both within Academic Practice and as a PhD Student. A brief summary of different types of Sketchnotes is discussed, together with details of how these have been used in practice, and evolved through practical experience. Examples are shared that highlight how Sketchnotes have been used within PhD studies and scholarly practices. Creating Sketchnotes have enabled an understanding of thought processes and facilitated open communication to others in terms of $\mathrm{PhD}$ research. Sketchnotes have also helped with retention of information and engagement. Through incorporating Sketchnotes into everyday practice, this has fostered connections with others and enabled communication of complex ideas visually. This reflective piece contributes to insights and deepens understanding in the area of visual representation in learning and teaching.
\end{abstract}

Keywords: Sketchnotes, Visual Representation, imagery, PhD Research, Academic Practice 


\section{Introduction}

Sketchnotes are a form of visual representation. They can be thought of as a 'handdrawn visualization made on paper or tablet, created within a short time frame' (Nørgaard, 2017, p. 2). Mike Rhodes describes them as 'rich visual notes created from a mix of handwriting, drawings, hand-drawn typography, shapes and visual elements like arrows, boxes and lines' (Rhodes, 2014, p. 4).

The style of sketchnotes can range from a scientific, technical nature to a more creative style (Fernández-Fontecha et al., 2019, p. 7). The scientific approach can be useful in sense-making when attending technical presentations as Rob Dimeo explains in his own reflections in relation to sketch noting (Dimeo, 2017). Dimeo reflects that he became involved in sketch noting as a way of making sense of his own understanding. Dimeo provides advice on his blog in relation to sketchnoting scientific talks which include recommendations to 'relax, listen more, write less, read relevant material in advance of the talk, develop / guess a few elements [of his] visual library and sketch a rough draft live and refine or redraw after [the] talk' (Dimeo, 2017).

An alternative to the 'scientific' type is the more creative type of sketchnote. Lorraine Kasyan talks about the fact that a sketchnote is invested in, cared about, and experienced fully [and that] just once glance would probably create that spark of understanding leading you directly back to the knowledge you seek' (Kasyan, 2020). I think on balance that the style of sketchnote that I create is probably more creative than scientific.

They can therefore vary in their scope, purpose and design. Norgaard argues that sketchnotes have a 'feel' and that they 'feel informal, like it has been produced quickly by a playful and light hand' (Nørgaard, 2017, p. 3). This can be compared with the more professional style of what I would term 'graphic-recording', often carried out by a professional artist who has been commissioned to portray the proceedings of an event or conference in visual format. Creating sketchnotes can help learners understand and retain key concepts and see relationships between them (Altieri, 2017) However, you don't have to be an artist in order to create a sketchnote (Sturdee, Lewis and Marquardt, 2018). I am certainly not an artist. The point is, that a sketchnote consists of ideas and thoughts which are captured on paper.

\section{Reflections on how I started making Sketchnotes}

The thought of sketchnotes being made with both creativity and care is something that resonates with me. I care about my sketchnotes, and invest time and energy in them. I like to think I am being creative however they may not be the prettiest sketchnote in the world and they might look confused to others on occasions. They are however, personal and unique to me and therefore have purpose. Some of my early ones do look less 'cared' for and creative than others however. It is useful to look back on those as I can see elements of progression over the years.

Sometimes I share my sketchnotes on social media, usually on twitter or on my blog. I should add here that although I may choose to share some of my sketchnotes through social media, I do not expect that they will mean much to anyone else. I create them for different purposes, some are for note taking purposes, others are where I am trying

International Journal of Management and Applied Research, 2020, Vol. 7, No. 3 
to work out conceptual aspects or connections. I use sketchnotes to generate ideas and as a memory aid, as well as to help me focus in situations like conference sessions. They are personal and unique to me. For me, making a sketchnote, allows me to map out key thoughts that are in my head. I also find it keeps me engaged. The act of using icons, symbols and words with different fonts and colours, makes it much more interesting and I think helps me retain things more easily. I wonder whether this could be explained by Dual Coding Theory (Clark and Paivio, 1991).

I first became involved with Sketchnotes through seeing other people do them and share them at academic conferences. I was fascinated by how people could listen and summarize thoughts and ideas from keynote speakers and translate this into an image. I was encouraged by others around me at the time who were also experimenting with Sketchnotes and sharing photographs of them on Social Media, so I just decided to give it a go too. My early attempts at Sketchnotes (Figure 1) were created on paper with whatever I had to hand at the time. I don't think I was particularly prepared for it.

Figure 1: Sketchnotes with Pencils seem more like scribbled notes

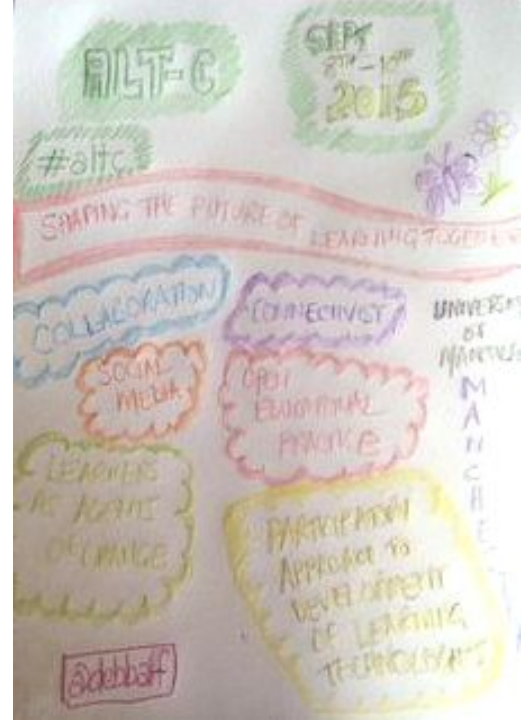

Sometimes this meant that they were drawn in pen or even coloured pencils if that was what I had available. I found through trial and error though that if I used a biro pen or coloured pencil, this meant that I tended to slip into the habit of just writing on the page and didn't really make much effort with trying to actually visualize what I was trying to make a note about. I also think that the coloured pencil ones I did initially are a bit boring and hard to read as they are quite pale in colour. They also don't really include many images and as such I think some of my early attempts convey more of a feel of 'scribbled' coloured notes rather than Sketchnotes when compared with ones that I have done more recently.

Despite my early amateur attempts, I was really excited by the potential of using Sketchnotes though and wanted to try and improve my skills. I came across a free practical workshop that was offered a few years ago by the brilliant Eleanor Beer (www.instagram.com/eleanorbeer). Attending Eleanor's workshop really gave me the confidence to start experimenting a bit more. Eleanor supplied the participants with an

International Journal of Management and Applied Research, 2020, Vol. 7, No. 3 
A4 Sketchpad and a Sharpie felt tip pen. I found that using a Sharpie gave a much more vivid result.

Figure 2: Extract from Sketchnoting Workshop Practice

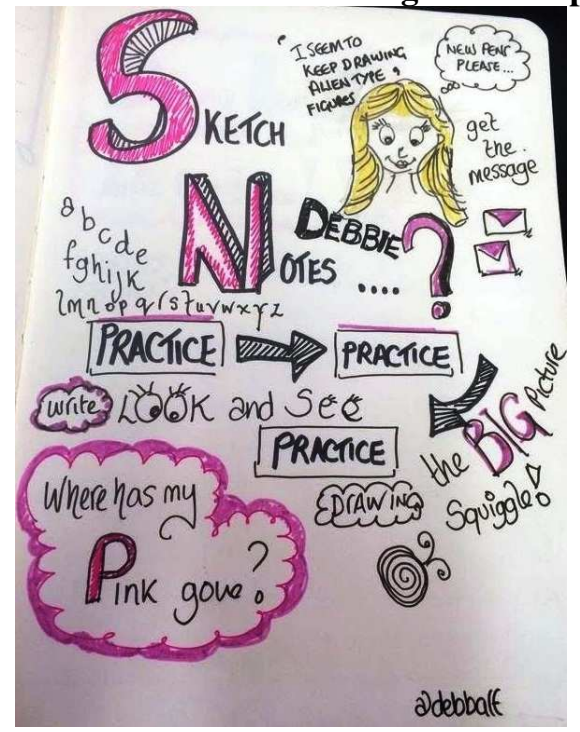

Switching to using felt tip pens as I gained more experience seemed to encourage my brain to be a bit more creative, and this meant that I started using a couple of images. I bought a great book called the 'Sketchnoting Handbook' by Mike Rhodes (Rhodes, 2014) and this really helped in terms of lettering and composition. I practiced by making random notes and I started to experiment with different fonts and using accent colours and shading to make things stand out (Figure 3). I found the Sketchnote Army (www.sketchnotearmy.com) through Mike and would highly recommend the resources available.

Figure 3: Random Sketchnote in 2016 showing single accent colour and use of icons

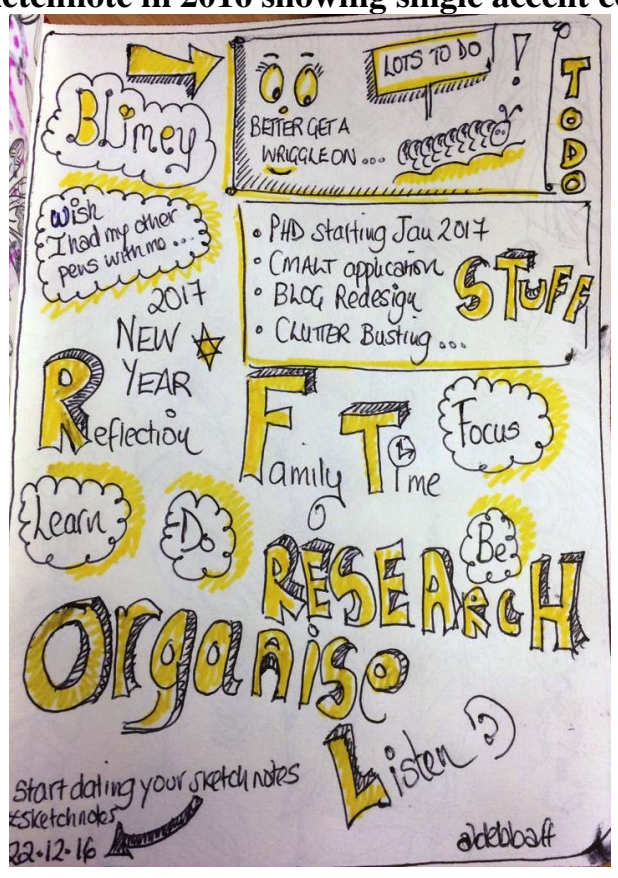

International Journal of Management and Applied Research, 2020, Vol. 7, No. 3 
I found that creating Sketchnotes on paper was absolutely fine, although it did mean of course that any 'mistakes' are on view more easily. I started to notice that other people were using a mobile device or tablet such as an iPad to create their Sketchnotes. Using devices like these not only allowed an infinite availability of colours, it also meant the ability to change my mind or correct things easily which can be so helpful. So, when I was fortunate enough to get an iPad, I started experimenting with different drawing apps. One of the first ones I used was Paper, a product of FiftyThree (www.fiftythree.com). I noticed that other people were using a stylus to draw on their iPad's, so I bought the one recommended on the Paper app. Initially though, it took a bit of practice trying to get the stylus to write anything legible as it had a fairly soft point to it, and I never thought I would get the hang of it, however after a short while I much found it easier to use (Figure 4).

Figure 4: Early sketchnote using iPad and Apple Pencil - Done with ZoomNotes

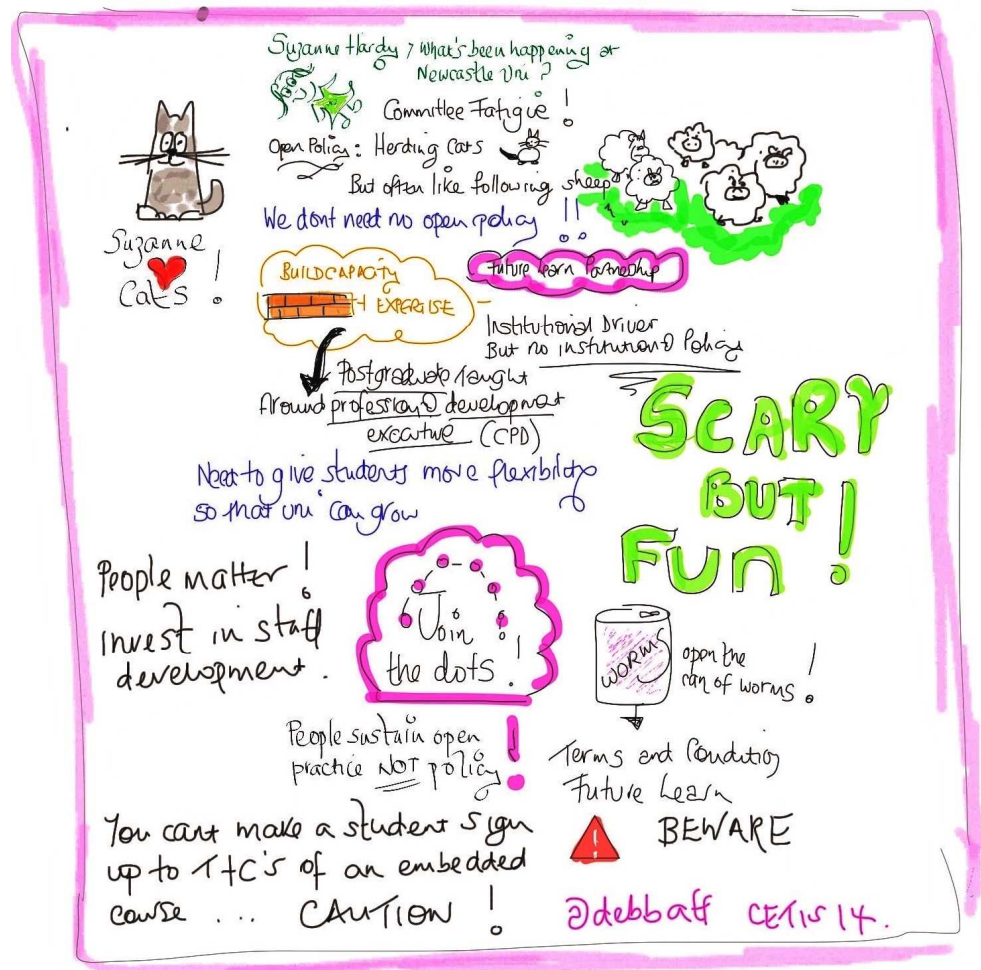

Fast forward to 2020 and I probably do $90 \%$ of my sketchnotes using an Apple Pencil and iPad. Over the years I have experimented with different apps including Paper, (www.fiftythree.com), Photoshop Sketch (www.adobe.com/uk/products/sketch.html), Autodesk SketchBook (www.sketchbook.com/), Procreate (www.procreate.art/), ZoomNotes (https://apps.apple.com/gb/app/zoomnotes/id462234530), Concepts (https://concepts.app/en/), and Inkflow (www.qrayon.com/home/inkflow/). They all have various merits and some offer free versions which are robust. I would recommend trying lots of different apps as some are more useful for certain things, and although some of the ones that use layered functionality have a steeper learning curve, they can be impressive. I tend to favour Paper and Procreate as these are the ones I have most experience with, although I have recently come across GoodNotes (www.goodnotes.com) which I absolutely love.

International Journal of Management and Applied Research, 2020, Vol. 7, No. 3 


\section{Reflection on using Sketchnotes as a Practitioner}

As a former Senior Academic Developer, I have used Sketchnotes within my working life and uses have included meeting notes, conference session summaries, interview preparation, planning and visual representation of different frameworks. Although these were made for different purposes, they have in common a shared set of ideas and thoughts that I am trying to represent visually such as taking notes at conference session presentations (Figures 5 and 6).

Figure 5: Sketchnote of a Keynote Talk, by Sam Twissleton at \#SOCMEDHE19 Made with Paper53

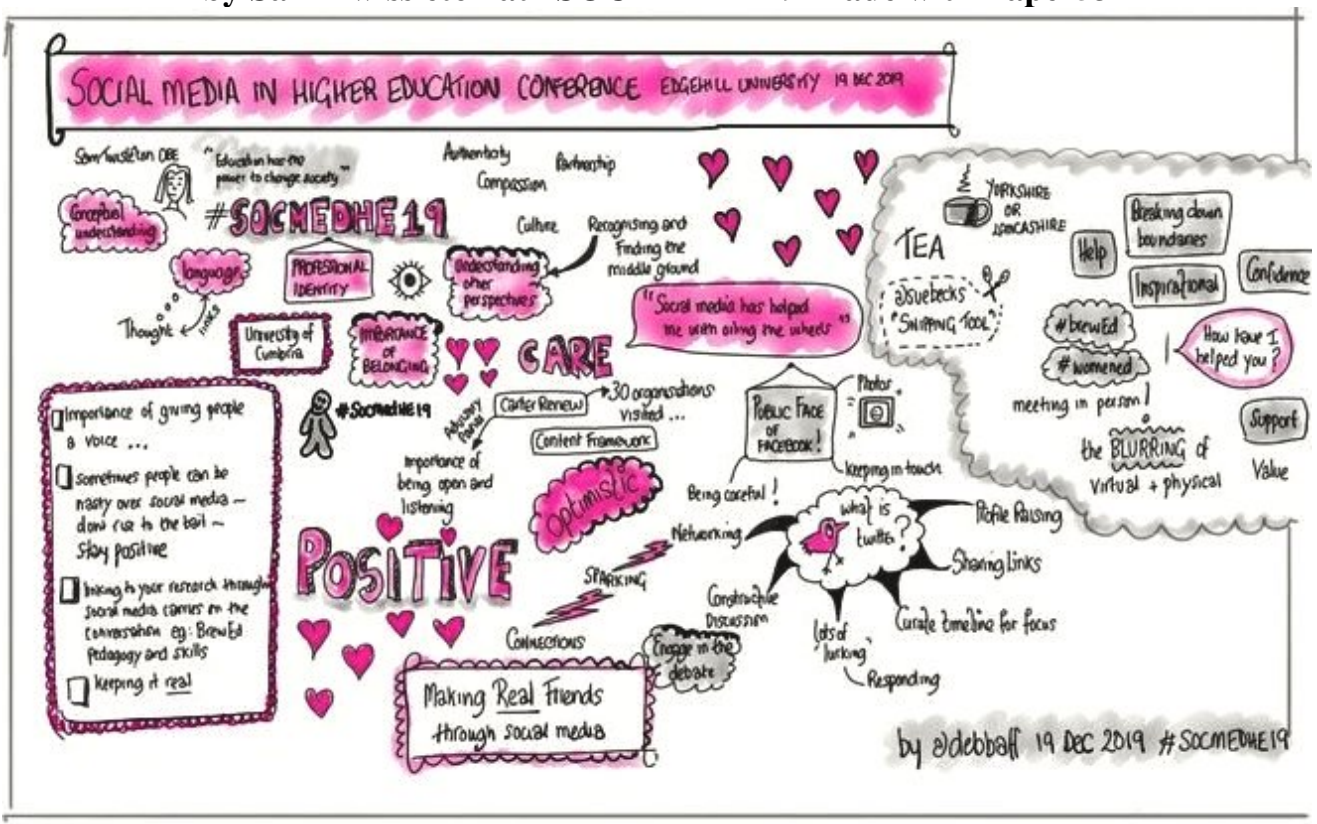

Figure 6: Sketchnote of Keynote by Maren Deepwell Made with Paper 53

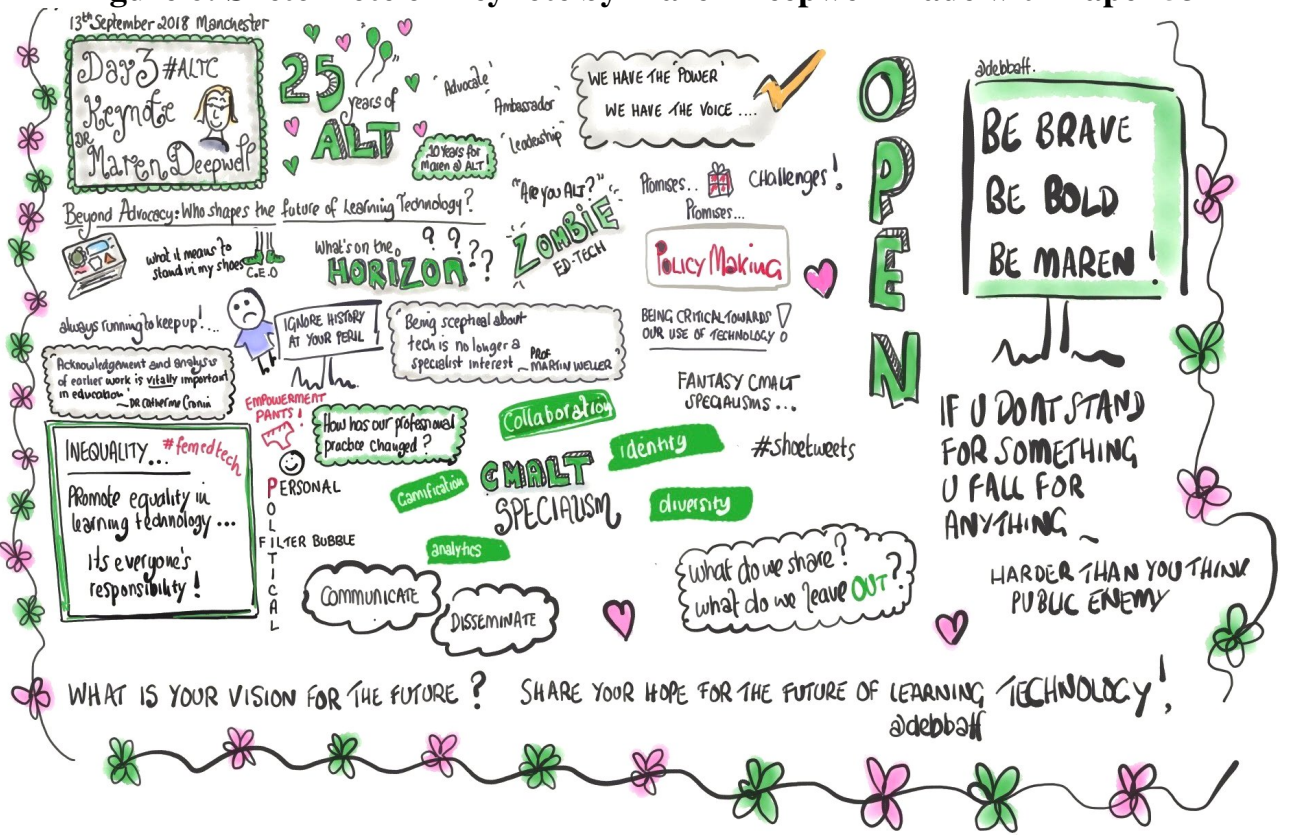

International Journal of Management and Applied Research, 2020, Vol. 7, No. 3 
I found some additional benefits through taking Sketchnotes at conferences as when I started sharing them on social media, usually through Twitter, I found that my tweets with Sketchnotes tended to be retweeted, or in some cases commented upon (mostly in a good way!).

This has led to making connections with people that I may not have met otherwise. I do try to tag the person giving the talk when I tweet as sometimes, I find they are happy to find that someone has done a Sketchnote of their talk. It's a great way of being creative, making connections and giving back and at the same time keeping engaged while making notes.

My interest in Sketchnotes has also led to requests from others that I create something specific for them. For example, I was asked to draw a picture of a Continued Professional Development (CPD) Framework in 'sketchnote' style at my previous institution. This was subsequently used on the departmental website (See Figure 7)

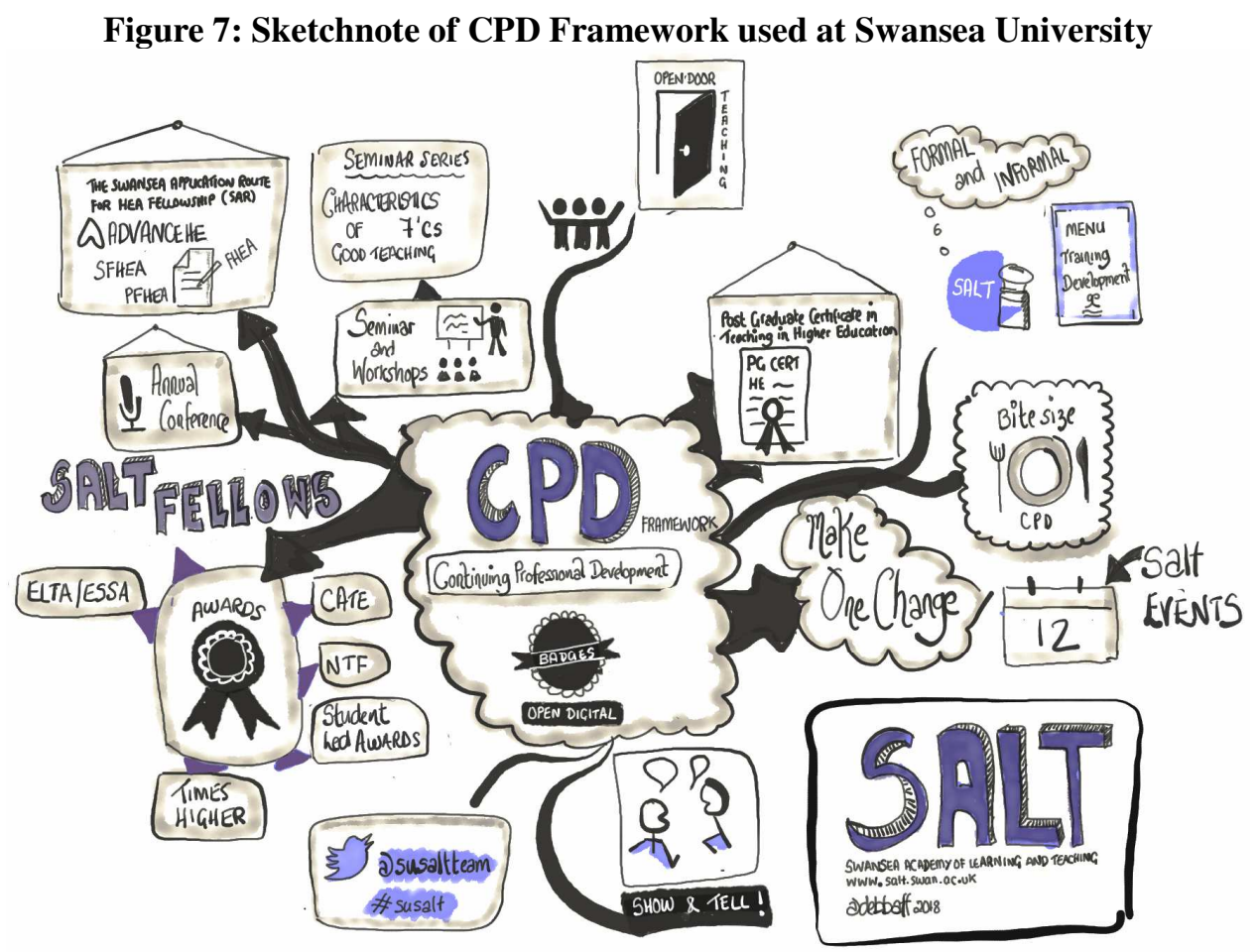

\section{Reflections on using Sketchnotes for PhD Study}

In my $\mathrm{PhD}$ Studies, I have used Sketchnotes to take notes on journal articles and find that this helps with some of the more complex ideas that I come across. In the example below I have created a Sketchnote of my take on a paper about Affinity Spaces (Gee 2004). I have used the approach of using a single accent colour, purple to make things stand out (Figure 8). I find that using Sketchnotes for summarising articles has a couple of benefits, it keeps me engaged, particularly when the article requires a fair bit of heavy lifting to unpick some of the finer details, and also it definitely helps it 'stick' in my memory as I will remember how it looks on the page.

International Journal of Management and Applied Research, 2020, Vol. 7, No. 3 
Figure 8: Affinity Spaces - Gee 2004 Sketchnote Made with Good Notes

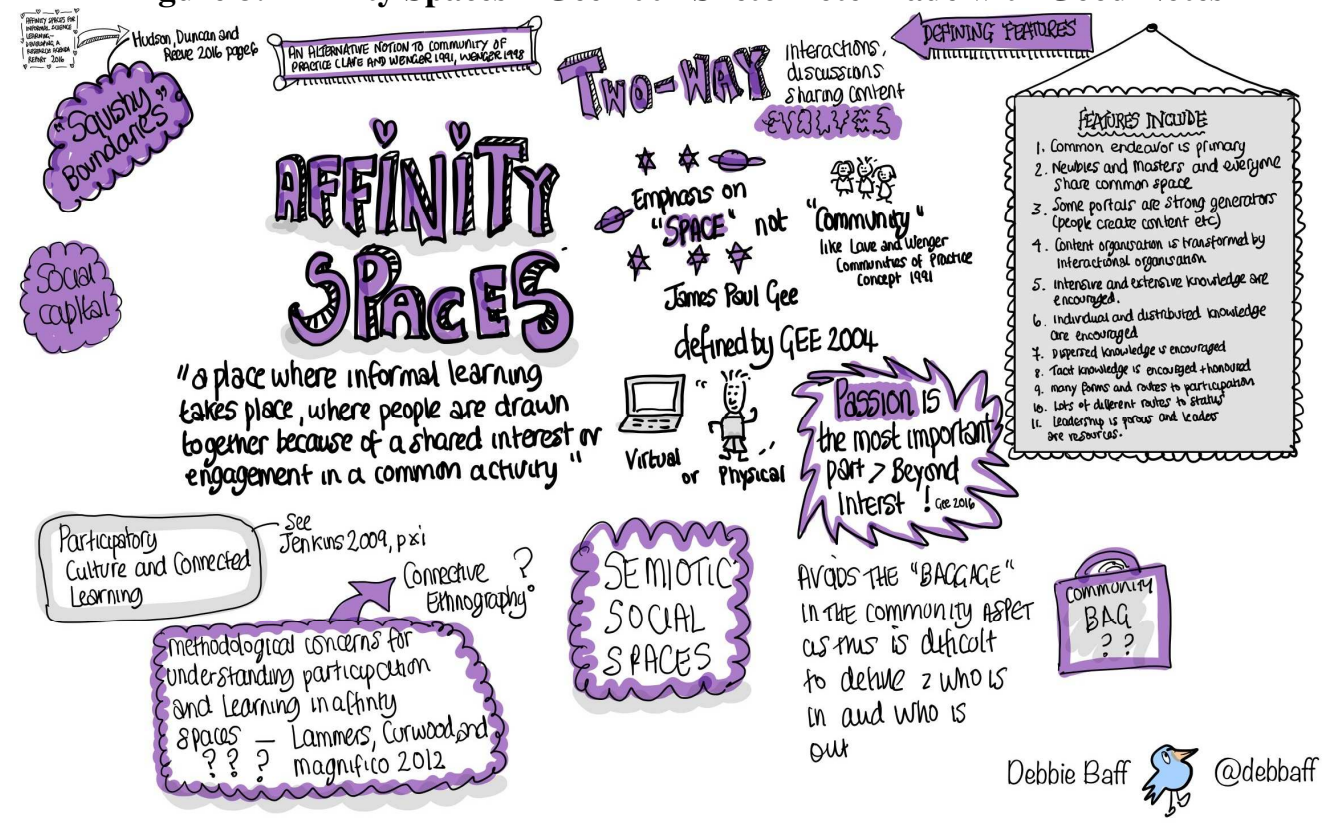

I have also used Sketchnoting to try and make sense of my PhD Research Proposal and this helped me articulate some of what I was trying to explain. Figure 9 shows my thoughts at the time. This particular Sketchnote shows how I have evolved in terms of skill and using borders, frames, accent colours, shading and images to portray different ideas. I found this useful as an aide memoire in writing notes for my supervisor.

Figure 9: My Idea for PhD Research Sketchnote (Baff 2020) Made with Procreate

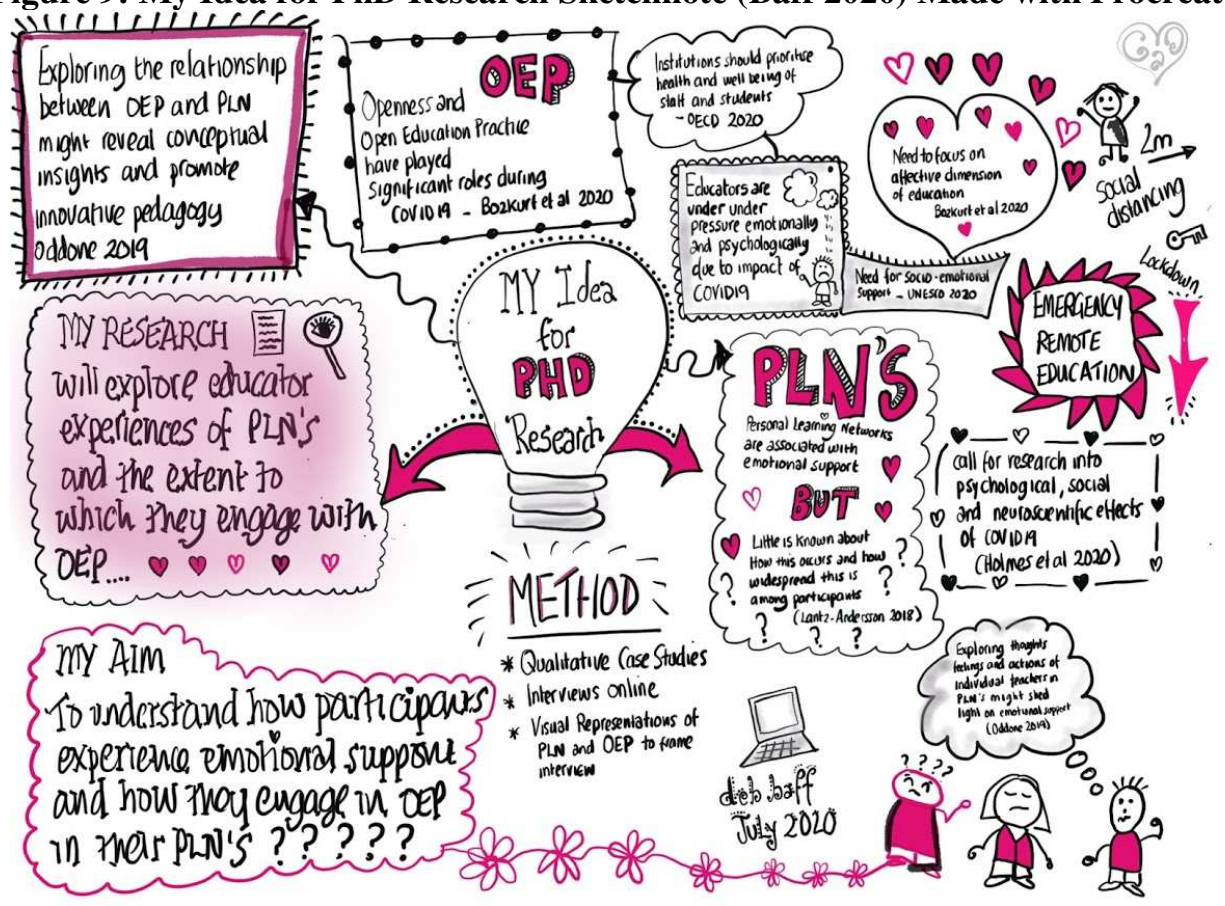

International Journal of Management and Applied Research, 2020, Vol. 7, No. 3 
The act of getting my thoughts down on paper also helped me realise that what I am interested in researching, has come from within me and my own experience. Seeing this on paper led me to investigate different methodological approaches that could offer a way of including the researcher's own experience. I am therefore now investigating the use of Heuristic Inquiry (Moustakas, 1990).

In order to try and make sense of the various parts within Heuristic Inquiry I have since made a Sketchnote which allows me to see the connections between some of the key concepts and enables me to have a quick reference guide to refer to when in meetings with my supervisor (Figure 10).

Figure 10: Heuristic Inquiry Sketchnote of notes from article by Kenny (2012), Made with Good Notes

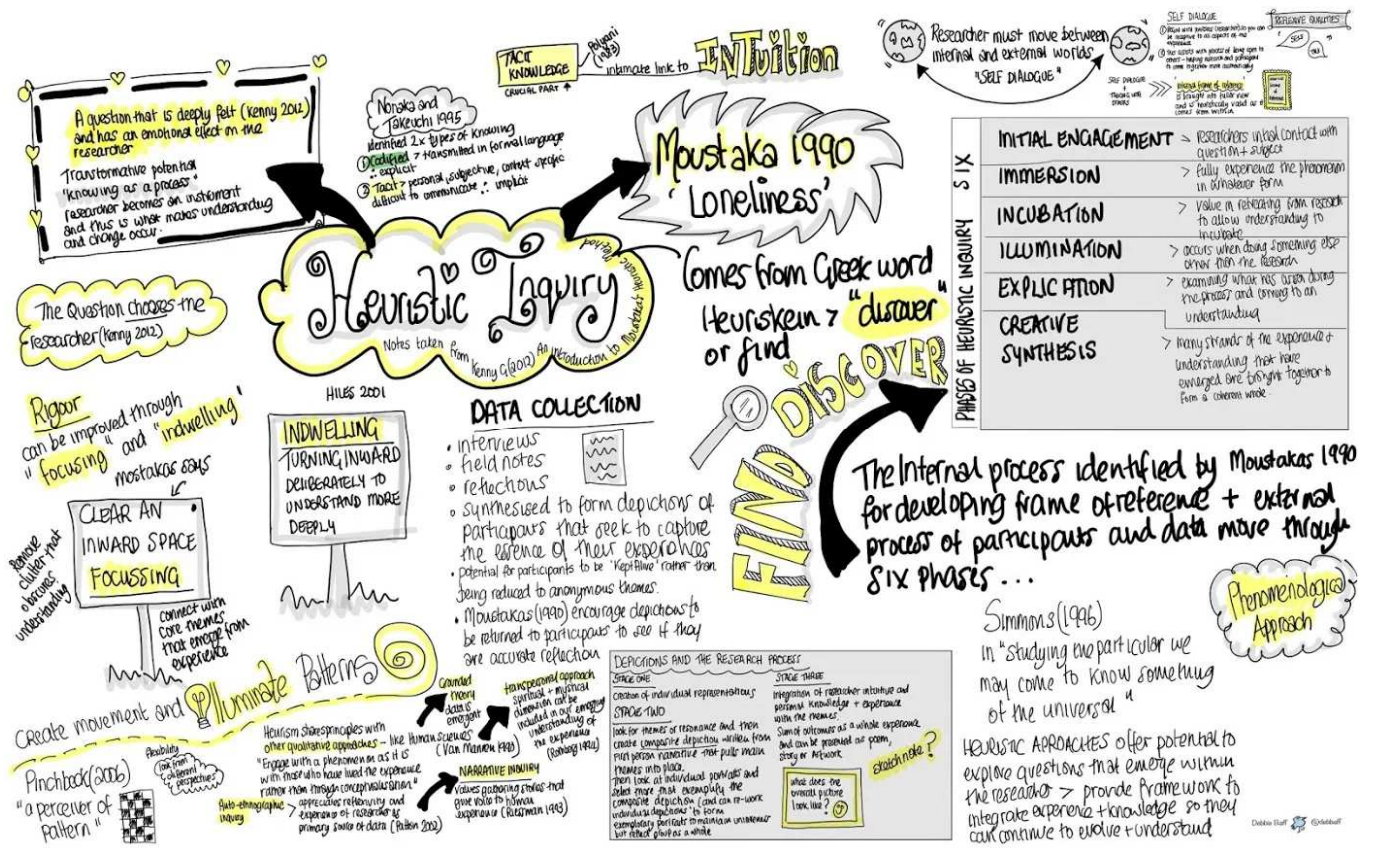

As can be seen in Figure 10, the use of a single colour of yellow for accenting key areas and using icons, boxes and frames help to provide a structure for the Sketchnote.

Writing this paper has meant that I had to revisit some of my early sketch notes and that meant that I had to try and find them. This is one area that I wish I had been more organized with. Because I have used both paper and an iPad to create my Sketchotes, and haven't shared all of them on social media, I found it difficult to track them all down. However, in order to try and curate them all in a place I have now set up an online virtual 'bulletin board' (Baff, 2020) and uploaded copies on that. I have tried to organise them by year so that I could see how I have evolved over the years. This was an interesting and quite a useful exercise as I can see that only my later sketch notes have the subject or title noted on them and a date. When I create Sketchnotes now, the first thing I do is to draw the title and make this stand out on the page, I also add the date and any other relevant details, and I also tend to include my twitter handle.

International Journal of Management and Applied Research, 2020, Vol. 7, No. 3 
As is probably quite evident, my early attempts at Sketchnotes were quite raw, but I can see how I have grown in my more recent attempts. I have learnt so much from people that I truly admire such as Mike Rhodes (www.rohdesign.com), Rob Dimeo (www.twitter.com/Rob Dimeo), and Sylvia Duckworth (www.sylviaduckworth.com). I can see elements of progress over the years in terms of both my own style and skill thanks to implementing ideas from others. While I will never consider myself on a par with accomplished 'sketchnoters', I do feel that I have made advances over the last few years and these in turn have helped me make sense of my $\mathrm{PhD}$ studies and my practice.

The fact that my Sketchnotes are so personal to me adds a layer of vulnerability if I choose to share my Sketchnotes on social media. I think therefore this would explain why I didn't share many of my early Sketchnotes online when I first started doing them. It took quite a leap of faith to decide that I should share my 'scribbles' as I call them on social media. In fact, it was an encouraging comment from Sheila MacNeill, a then fellow participant at a conference (who is now one of my good friends) who gave me the confidence to share. In doing so, I have received some lovely feedback and it is great to know that some of my scribbles have been of some sort of use to other people.

\section{Conclusion}

In conclusion, I have found that creating Sketchnotes as part of my Academic Practice and specifically during my $\mathrm{PhD}$ journey has been very effective. By using text and images to create something individual and personal to me, this has helped me make sense of complex concepts and see connections that might have been otherwise difficult to identify. Using Sketchnotes to make notes while attending conferences has enabled me to stay focused and engaged on presentations and record an aide memoir to capture key points that the presenter has made. Sharing my Sketchnotes on social media has enabled me to make connections with others that may not have been made otherwise and has also allowed my research to be more visible.

There are therefore many advantages to use of Sketchnotes within PhD Research and Academic Practice however one potential disadvantage is misunderstanding that Sketchnotes can only be done by 'creative' people. I would maintain that to create a Sketchnote, you do not need to be an artist, or even be able to draw, all you need is to use your imagination to highlight key ideas and connections and use simple imagery such as stick figures or shapes to represent concepts on the page. I plan to use Sketchnoting in my future research to draw out key themes and connections as my research develops. I also intend to use it to plan my meetings with my supervisor and to sketch out chapter contents and the framework for my thesis. I can see potential for supervisors to perhaps use a Sketchnoting approach with other doctoral students. This could include creating a Sketchnote to outline preliminary ideas, or to show connections in a literature review. It could also be used in group settings to review journal articles and provide summaries.

\section{Acknowledgements to:}

Dr Maren Deepwell Keynote; Sam Twissleton OBE Keynote; Eleanor Beer; Mike

Rhodes; Rob Dimeo; Sheila MacNeill (https://twitter.com/sheilmcn); Sketchnote Army and Sylvia Duckworth.

International Journal of Management and Applied Research, 2020, Vol. 7, No. 3 


\section{References}

1. Altieri, J. L. (2017), "From Sketchnotes to Think-Alouds: Addressing the Challenges of Social Studies Text", Social Studies and the Young Learner, Vol. 30, No. 1, pp. 8-12.

2. Baff, D. (2020), Debs \#Sketchnotes: A collection of my scribbles [Online] Available at: https://padlet.com/Debbaff/sketchnotes [Accessed on 31 July 2020].

3. Clark, J.M. and Paivio, A. (1991), "Dual coding theory and education", Educational psychology review, Vol. 3, No. 3, pp.149-210. https://doi.org/10.1007/BF01320076

4. Dimeo, R. (2017), "Sketchnote summary of The backscattering story: A personal view'," Journal of Neutron Research, Vol. 19, No. 3-4, pp. 103-105. https://doi.org/10.3233/JNR-160030

5. Fernández-Fontecha, A.; O’Halloran, K. L.; Tan, S. and Wignell, P. (2019), “A multimodal approach to visual thinking: the scientific sketchnote", Visual Communication, Vol. 18, No. 1, pp. 5-29. https://doi.org/10.1177/1470357218759808

6. Gee, J.P. (2004), Affinity spaces. Situated language and learning: A critique of traditional schooling, New York: Routledge.

7. Kasyan, L. (2020), "The power of visuals in learning is deeply rooted", Sketchnote Army. [Online] Available at: https://sketchnotearmy.com/blog/lorraine-kasyanvisuals-in-learning [Accessed on 31 July 2020].

8. Kenny, G. (2012), "An introduction to Moustakas's heuristic method", Nurse Researcher, Vol. 19, No. 3, https://doi.org/10.7748/nr2012.04.19.3.6.c9052

9. Nørgaard, M. (2017), "Can you picture this? Instructions for using Sketchnotes to help novices improve their design sketching skills", presented at: 10th International Conference of Education, Research and Innovation, Spain, 16-18th November 2017. https://doi.org/10.21125/iceri.2017.0605

10. Moustakas, C. E. (1990), Heuristic research: design, methodology, and applications, USA: Sage Publication. https://doi.org/10.4135/9781412995641

11. Rhodes, M. (2014), The Sketchnote Handbook: the illustrated guide to visual note taking. USA: Peachpit Press.

12. Sturdee, M.; Lewis, M. and Marquardt, N. (2018), "Sketchblog \#1: The Rise and Rise of the Sketchnote", Interactions, Vol. 25, No. 6, pp. 6-8.

https://doi.org/10.1145/3281661

\section{Sketchnotes}

1. Figure 1 "Sketchnotes with Pencils seem more like scribbled notes" by Debbie Baff is licensed under CC BY 4.0 (https://creativecommons.org/licenses/by/4.0/)

2. Figure 2 "Extract from Sketchnoting Workshop Practice" by Debbie Baff is licensed under CC BY 4.0 (https://creativecommons.org/licenses/by/4.0/)

International Journal of Management and Applied Research, 2020, Vol. 7, No. 3 
3. Figure 3 "Random Sketchnote in 2016 showing single accent colour and use of icons" by Debbie Baff is licensed under CC BY 4.0 (https://creativecommons.org/licenses/by/4.0/)

4. Figure 4 "Early sketchnote using iPad and Apple Pencil - Done with Zoomnotes" by Debbie Baff is licensed under CC BY 4.0 (https://creativecommons.org/licenses/by/4.0/)

5. Figure 5 "Sketchnote of a Keynote Talk by Sam Twissleton at \#SOCMEDHE19 Made with Paper53" by Debbie Baff is licensed under CC BY 4.0 (https://creativecommons.org/licenses/by/4.0/)

6. Figure 6 "Sketchnote of Keynote by Maren Deepwell Made with Paper 53" by Debbie Baff is licensed under CC BY 4.0 (https://creativecommons.org/licenses/by/4.0/)

7. Figure 7 "Sketchnote of Continued Professional Development Framework used at Swansea University" by Debbie Baff is licensed under CC BY 4.0 (https://creativecommons.org/licenses/by/4.0/)

8. Figure 8 "Affinity Spaces - Gee 2004 Sketchnote Made with Good Notes" by Debbie Baff is licensed under CC BY 4.0 (https://creativecommons.org/licenses/by/4.0/)

9. Figure 9 "My Idea for PhD Research Sketchnote (Baff 2020) Made with Procreate" by Debbie Baff is licensed under CC BY 4.0 (https://creativecommons.org/licenses/by/4.0/)

10. Figure 10 "Heuristic Inquiry Sketchnote of notes from article by Kenny (2012) Made with Good Notes" by Debbie Baff is licensed under CC BY 4.0 (https://creativecommons.org/licenses/by/4.0/)

11. All Sketchnotes are by Debbie Baff (@ Debbaff) and can be found at https://padlet.com/Debbaff/sketchnotes 